\title{
Surface roughness on the Greenland ice sheet from airborne laser altimetry
}

\author{
C.J. van der Veen \\ Byrd Polar Research Center, The Ohio State University, Columbus OH 43210
}

\author{
W.B. Krabill \\ NASA, GSFC/Wallops Flight Facility, Wallops Island VA 23337 \\ B.M. Csatho and J.F. Bolzan \\ Byrd Polar Research Center, The Ohio State University, Columbus OH 43210
}

\begin{abstract}
High resolution airborne laser altimetry is used to determine the small-scale surface relief in central Greenland and estimate the contribution from spatial noise to stratigraphic records. The standard deviation of the surface roughness is $1.6 \mathrm{~cm}$ water equivalent, corresponding to a standard deviation of annual layer thickness of $2.3 \mathrm{~cm}$ we. This estimate agrees with an independent assessment of the spatial variability $(2.5 \mathrm{~cm}$ we) based on nine shallow ice cores. The agreement suggests that the statistical nature of the surface in central Greenland remains unchanged throughout the year. By conducting airborne altimetry around proposed drilling sites, the expected noise level in the core can be evaluated and sites selected where this level is lowest.
\end{abstract}

\section{Introduction}

Ice cores provide excellent means to reconstruct historic time series of climate variables such as snow accumulation. To establish high-resolution time scales, annual layers are identified, either visibly (Gow, 1965; Palais and others, 1982) or by measuring the chemical composition of core samples (Mosley-Thompson, 1980; Palais and others, 1982). Derived accumulation records show great variability from year-toyear, making it difficult to separate natural periodicities that are climatically significant from random noise.

The two processes contributing to noise in ice-core records are interannual climate variations and small-scale irregularities in the snow surface that are preserved in the stratigraphic record. For a correct interpretation it is important to separate these two contributions and obtain information on the noise level and spectrum associated with each. In this study, surface irregularities leading to spatial noise are considered and in particular, how this noise affects the thickness of annual layers.

The issue addressed here is important for interpretation of changes in ice-sheet surface elevation measured by repeat altimetry over comparatively short periods. Interannual variability in accumulation may lead to apparent trends in ice thickness that could be erroneously interpreted as climatically significant (Van der Veen, 1993). To evaluate the importance

\section{Copyright 1998 by the American Geophysical Union.}

Paper number GRL-1998900041.

0094-8276/98/GRL-1998900041\$05.00 and magnitude of natural variations in surface elevation, the noise level associated with temporal fluctuations in accumulation rate needs to be known. This level can be estimated from the observed variability in accumulation records if an estimate for the contribution associated with spatial variability is available or can be made.

Small-scale surface irregularities are associated with sastrugi and other wind-formed features. Generally, these form over hours to days and can persist for months once agehardening (sintering) has occurred (Watanabe, 1978). Other than forming in the prevailing wind direction, there is no evidence suggesting that the formation of sastrugi is anything but a random process. This surface relief may be levelled by subsequent wind action or sublimation (Gow, 1965) thus reducing the amplitude of the spatial noise. To study this effect, repeat altimetry missions throughout the year are needed. Such data are not available, necessitating the assumption that the statistical nature of the irregularities remains the same throughout the year so that the roughness of the surface observed at any given time is representative of the roughness at any other times. This allows the spatial noise in ice-core records to be evaluated from estimates of the surface roughness. The result obtained for central Greenland justify a posteriori the assumption of constant spatial noise.

There are few measurements relating to small-scale surface relief. Long (1961) shows contour maps of the relative surface elevation in a 100 by $100 \mathrm{~m}$ study area near Byrd Station, West Antarctica, determined from the relative elevations of 250 dowels placed in the snow, $\sim 6 \mathrm{~m}$ apart. The maximum relief of the surface is $28 \mathrm{~cm}$. Near Dome C, East Antarctica, Palais (1980) measured relative elevations at six different times in a "bamboo forest" consisting of poles placed $3 \mathrm{~m}$. apart in a 10 by 10 grid. The average standard deviation of, the surface obtained from these six measurements is $6 \mathrm{~cm}$ of firn, or $\sim 2 \mathrm{~cm}$ of water equivalent. Andreas (1995) shows a surface profile obtained by levelling at a sampling interval of $0.5 \mathrm{~m}$. However, these measurements were conducted on a large ice floe drifting in the Weddell Sea and may not be representative of conditions in the interior of ice sheets.

The traditional methods used to map small-scale surface relief are labor-intensive and necessarily restricted to small areas. With the development of accurate remote-sensing techniques this situation has changed. Airborne laser altimetry allows mapping of the snow surface with an accuracy of 10-15 cm over flightlines of several hundred kilometers 


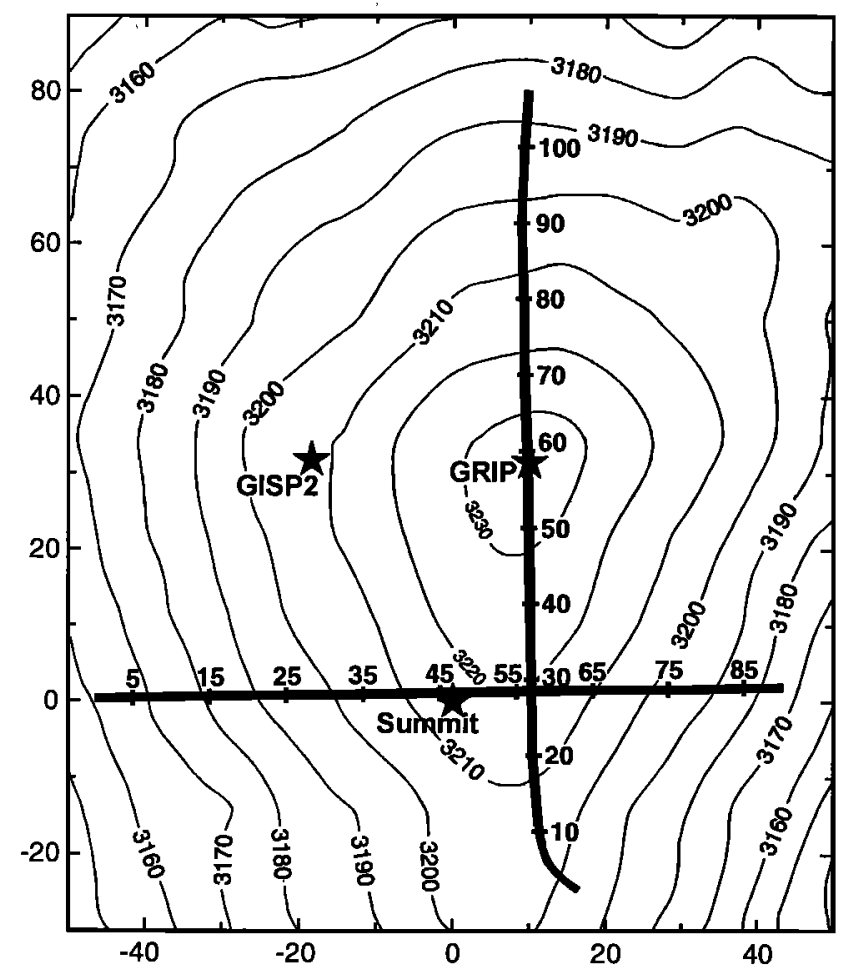

Figure 1. Location map. Elevation contours (interval: $10 \mathrm{~m}$ ) are based on airborne radar sounding (Hodge and others, 1990). The two heavy lines represent the two altimetry flightlines used in this study.

(Krabill and others, 1995). In this study, profiles measured along two perpendicular flightlines are used to investigate the nature of small-scale surface relief. The area selected is the Summit region in central Greenland and includes the U.S. (GISP2) and European (GRIP) deep drilling sites (Figure 1). The motivation for choosing this area is the availability of ancillary measurements, in particular nine 30-year accumulation records (Bolzan and Strobel, 1994). The spatial variability derived from these records is discussed elsewhere (Van der Veen and Bolzan, subm.) and provides an independent check on the results obtained from the altimetry data.

\section{Airborne laser data acquisition}

The data were collected on May 22, 1995, as part of a NASA program to map the surface of the Greenland Ice Sheet. The sensor for these flights was the Airborne Topographic Mapper (ATM), a series of instruments which combines high pulse rate laser ranging with a scanning capability (Krabill and others, 1995). At the nominal operating altitude of $400 \mathrm{~m}$, the size of the illuminated footprint is $\sim 1 \mathrm{~m}$. At a pulse rate of $2000 \mathrm{~Hz}$ and a nominal speed of the aircraft of $125 \mathrm{~m} / \mathrm{sec}$ the resultant footprint spacing is $\sim 6 \mathrm{~cm}$. The ranging data for the ATM sensors are calibrated to better than $5 \mathrm{~cm}$. A few obvious outlier measurements were removed from the ranging data and to minimize the random measurement errors, averages of five adjacent data points are used to reconstruct the elevation of the snow surface. Other averaging schemes (such as Gaussian smoothing) were also considered but yielded essentially the same results.

In order to measure topography to the desired accuracy of $<10 \mathrm{~cm}$, the aircraft location must be known to $\sim 5 \mathrm{~cm}$ (horizontally and vertically). This accuracy was achieved using kinematic Global Positioning System (GPS) techniques (Krabill and Martin, 1987). GPS data sets were obtained with the aircraft parked close to the fixed receiver for about 45 minutes before and after each survey flight. These stationary data are used to resolve ambiguities in carrier phase for each frequency between the fixed and mobile receivers for subsequent application during the processing of the in-flight data. Additionally, local meteorological conditions (pressure, temperature and humidity) were recorded for application during post-mission processing. These data are combined with a precise ephemeris of the GPS constellation into a point-topoint range difference solution for the trajectory of the aircraft. For the flightlines used here, the baseline was $\sim 1000$ km from Kangerlussuaq on the west coast to Summit and the use of a precise post facto ephemeris (available from several sources on the internet) is required.

\section{Surface topography}

An extensive series of ice surface profiles was collected over a 180 by $180 \mathrm{~km}$ grid in the Summit region in 1987 as part of the GISP2 site-selection program (Hodge and others, 1990), using the Danish TUD airborne radar. Part of the high resolution topographic map is shown in Figure 1. Comparison between the laser-altimetry elevations and those obtained from the TUD radar shows good agreement except for a constant difference associated with different ellipsoid models used in deriving the two sets of elevations.

In the region covered by the flightlines, the surface elevation varies smoothly and there are no larger undulations associated with flow over bedrock irregularities. The bed in this region does not have an obvious ridge/valley structure and there are no large peaks that could produce surface effects (Hodge and others, 1990).

Of interest here are the small-scale topographic features. To obtain the local topography, each flightline is divided into $0.5 \mathrm{~km}$ sections. For each section, the large-scale slope is considered constant and the average surface represented by a straight line determined using least-squares fitting. The dif-

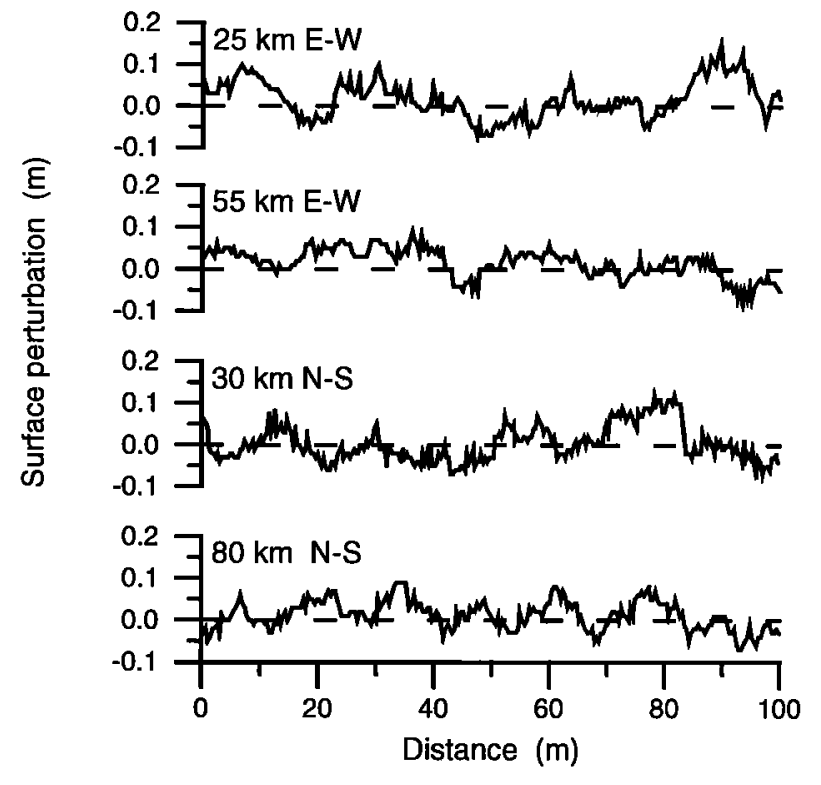

Figure 2. Surface irregularities for four selected segments of the two flightlines. 
ference between the actual elevations and this best-fit line represent small-scale perturbations. Examples are shown in Figure 2; for clarity, these examples cover only the first 100 $\mathrm{m}$ of selected $500 \mathrm{~m}$ sections.

The typical shape of sastrugi can be inferred from Figure 2 . The characteristic height, defined as the elevation difference between lows and highs, is less than $\sim 20 \mathrm{~cm}$ which agrees with casual visual inspection of the surface. The dominant wavelengths can be determined from spectral analysis of the data. There is some suggestion that certain dominant wavelengths exist (e.g. $\sim 45-50 \mathrm{~m}$ ), but the significance of such wavelengths, if real, is not clear.

Perhaps surprisingly, the profiles in Figure 2 do not indicate asymmetry. According to most observations, sastrugi are aligned with the mean wind direction with a gentle slope towards the wind and a steeper slope on their lee side. There may be two explanations for the observed lack of symmetry. First, neither of the two flightlines is necessarily aligned with the mean wind direction, and the symmetry may be lost in the profiles. Second, measurements of wind speed and direction using automatic weather stations show that there is considerable variation in the wind field in this region (Stearns and others, 1997). Perhaps this variability prevents the formation of distinctly asymmetric, aligned sastrugi.

\section{Surface roughness}

For interpretation of ice-core records, the important quantity is the roughness of the surface, or the standard deviation of the fluctuations in elevation from the slowly-varying mean. For the two flightlines, this quantity was determined for each $0.5 \mathrm{~km}$ segment and the results are shown in Figure 3. The average standard deviations are $4.5 \mathrm{~cm}$ of firn for the EastWest line and $4.0 \mathrm{~cm}$ of firn for the North-South line, with an uncertainty of $\sim 0.5 \mathrm{~cm}$. Using an average surface density of $370 \mathrm{~kg} / \mathrm{m}^{3}$, this corresponds to $1.7 \pm 0.2 \mathrm{~cm}$ water equivalent (we) and $1.5 \pm 0.2 \mathrm{~cm}$ we, respectively.

The North-South line is approximately aligned with the local ice crest, which may explain the smaller standard deviation compared to the East-West line. While the wind field in this region shows considerable variation, there appears to be some topographic control (Stearns and others, 1997). The ice-surface slope is primarily in the East-West direction and may induce somewhat larger wind speeds and associated surface roughness on the topographic flanks. The East-West line follows these slopes and the surface variability is largest at both ends of this line. The lower standard deviation at dis-

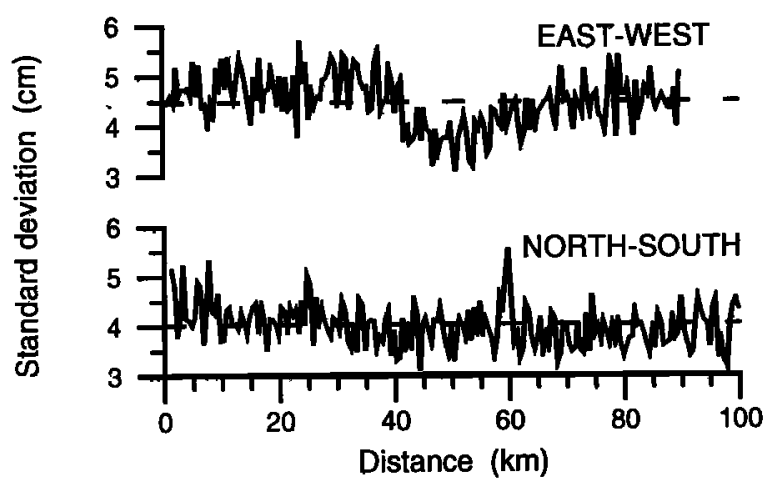

Figure 3. Standard deviation of small-scale surface roughness along the two flightlines.

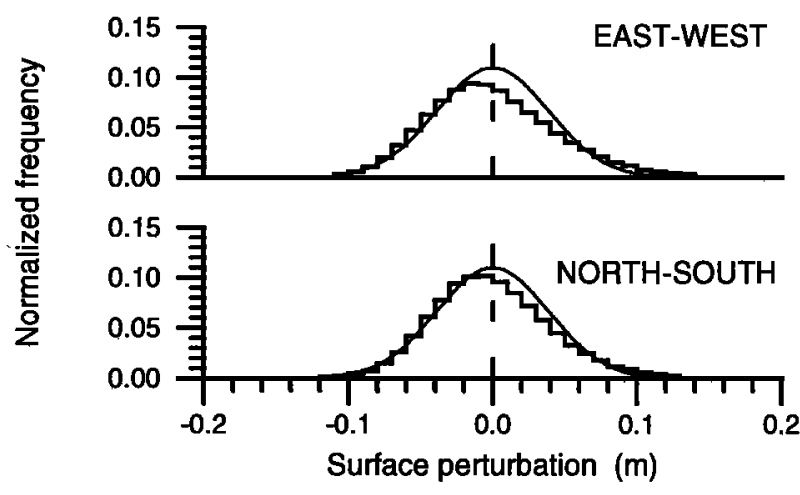

Figure 4. Frequency distribution of surface perturbations for both flightlines.

tance $40-60 \mathrm{~km}$ coincides with the position of the ice crest where the surface slope is near zero. The higher roughness on the west side of the crest may also be related to the generally higher accumulation rates in this area. Because about $90 \%$ of precipitation in central Greenland derives from synoptic-scale cyclones (Robasky and Bromwich, 1994), higher accumulation rates generally result from more frequent and/or intense storms.

In their noise model for annual layer thickness, Fisher and others (1985) assume that surface relief with length scales less than a few $\mathrm{km}$ can be described by a stationary Gaussian distribution. The frequency distributions obtained for the two flightlines (Figure 4) show some deviation from the Gaussian distribution. In particular, the most frequently occuring surface perturbation is negative and the distribution is somewhat asymmetric with a larger tail on the positive side. The significance of the asymmetry can be evaluated by considering the skew of both distributions (Press and others, 1992, p. 606). For the North-South line, the observed distribution is not significantly different from Gaussian; for the East-West line, the deviation from Gaussian is marginally significant.

\section{Annual layer thickness}

In ice-core records, the thickness of annual layers is determined from the distance between two consecutive summer or winter surfaces. In central Greenland, surface accumulation is sufficiently large to bury irregularities on the surface within one year and two annual layers may be considered independent. The small-scale irregularities in each surface can be described by a standard deviation, $\sigma_{\mathrm{s}}$, and the standard deviation of the layer thickness is $\sqrt{2} \sigma_{\mathrm{s}}$. For the two flightlines considered here, the standard deviation is $1.6 \mathrm{~cm}$ we, giving a standard deviation for the layer thickness of $2.3 \mathrm{~cm}$ we. This estimate is essentially the same as obtained by Van der Veen and Bolzan (subm.) from nine ice cores retrieved in this region.

The implicit assumption made here is that the surface measured at any time is representative for all other times. This may not be entirely correct since the surface characteristics may be different shortly after a storm event. After deposition, settling and erosion of sastrugi occurs, thus lowering the variability. At South Pole, the amplitude of surface relief is largest at the end of winter and decreases throughout the summer as dunes and sastrugi are gradually worn down by sublimation-deflation. Because most snow is deposited 
during the winter, the end-of-summer roughness is most representative of the spatial noise preserved in annual layers (Gow, 1965). This does not appear to be the case in central Greenland.

The estimate of surface roughness given in Van der Veen and Bolzan (subm.) is based on oxygen-isotope measurements in nine shallow firn cores. Isotope peaks correspond to summer temperature maxima and isotope troughs to winter temperature minima. Using summer-to-summer or winter-towinter surfaces to distinguish annual layers gives the same noise level associated with topographic irregularities. The agreement between surface roughness obtained from altimetry conducted in the spring, and that estimated from ice-core records for summer or winter surfaces, suggests that the variability of the surface does not change much with time in central Greenland.

\section{Conclusions}

The analysis presented here shows that high-resolution laser altimetry provides an accurate estimate for small-scale surface relief associated with sastrugi and wind dunes. The standard deviation of this surface roughness agrees well with the spatial noise preserved in the stratigraphic record, estimated from nine ice cores retrieved in the area considered. This suggests that, in central Greenland, no significant reduction in surface relief occurs during the summer.

Measuring surface roughness is important for the interpretation of high-resolution ice-core records because it allows the contribution from spatial noise to variability in these records to be estimated. The objective of ice-core records is to establish high-resolution time series of climate parameters and, preferably, the spatial noise should be minimized. Conducting studies similar to the present one over proposed drilling sites and in the upstream direction should be part of the siteselection procedure as it may provide information on the contribution of surface irregularities to the expected noise level in core records.

Moreover, the microrelief of the snow surface affects ventilation in the upper firn layers and may thus influence the concentrations of important geochemical tracers in ice cores. Waddington and others (1996) suggest that accurate measurements of surface topography should be combined with meteorological observations to study ventilation in firn and determine transfer functions for depositions of geochemical constituents. The present study demonstrates the feasibility of using airborne laser altimetry to describe the statistical nature of the snow surface on polar ice sheets.

Acknowledgements. Comments from E. Waddington and an anonymous reviewer helped improve the manuscript. Data collection was supported by the NASA Office of Polar Programs; interpretation was made possible by the U.S. National Science Foundation through grant no. OPP-9316509. Byrd Polar Research Center contribution no. C-1095

\section{References}

Andreas, E. L., A physically based model of the form drag associated with sastrugi, CRREL Report 95-16, U.S. Army Cold Re- gions Research and Engineering Laboratory, Hanover NH, 12 pp., 1995.

Bolzan, J. F. and M. Strobel, Accumulation-rate variations around Summit, Greenland, Journal of Glaciology, 40, 56-66, 1994.

Gow, A. J., On the accumulation and seasonal stratification of snow at the South Pole, Journal of Glaciology, 5, 467-477, 1965.

Fisher, D. A., N. Reeh and H. B. Clausen, Stratigraphic noise in time series derived from ice cores, Annals of Glaciology, 7, 7683, 1985.

Hodge, S. M., D. L. Wright, J. A. Bradley, R. W. Jacobel, N. Skou and $B$. Vaughn, Determination of the surface and bed topography in central Greenland, Journal of Glaciology, 36, 17-30, 1990.

Krabill, W. B. and C. F. Martin, Aircraft positioning using Global Positioning System carrier phase data. Navigation, 34, 1-21, 1987.

Krabill, W. B., R. H. Thomas, C. F. Martin, R. N. Swift and E. B. Frederick, Accuracy of airborne laser altimetry over the Greenland Ice Sheet, International Journal of Remote Sensing, 16, 1211-1222, 1995.

Long, W. E., Glaciology, Byrd Station and Marie Byrd Land traverse, 1958-1959, Project 825, Report No. 2, Part XI. The Ohio State Research Foundation, Columbus OH, 1961.

Mosley-Thompson, E., 911 years of microparticle deposition at the South Pole: a climatic interpretation, IPS Report No. 73, Institute of Polar Studies, The Ohio State University, Columbus $\mathrm{OH}$, 134 pp., 1980.

Palais, J. M., Snow stratigraphic investigations at Dome C, East Antarctica: a study of depositional and diagenetic processes, M.S. Thesis, The Ohio State University, Columbus OH, 146 pp., 1980.

Palais, J. M., I. M. Whillans and C. Bull, Snow stratigraphic studies at Dome C, East Antarctica: an investigation of depositional and diagenetic processes, Annals of Glaciology, 3, 239-242, 1982.

Press, W. H., S. A. Teukolsky, W. T. Vetterling and B. P. Flànnery, Numerical recipes (2nd. ed.), Cambridge University Press, Cambridge, 963 pp., 1992.

Robasky, F. M. and D. H. Bromwich, Greenland precipitation estimates from the atmospheric moisture budget, Geophysical Research Letters, 2l, 2495-2498, 1994.

Stearns, C. R., G. A. Weidner and L. M. Keller, Atmospheric circulation around the Greenland crest, Journal of Geophysical Research, $102(D), 13,801-13,812,1997$.

Van der Veen, C. J., Interpretation of short-term ice-sheet elevation changes inferred from satellite altimetry, Climatic Change, 23, 383-405, 1993.

Van der Veen, C. J. and J. F. Bolzan, Interannual variability in net accumulation on the Greenland Ice Sheet: observations and implications for mass-balance measurements, Journal of Geophysical Research, submitted.

Waddington, E. D., J. Cunningham and S. L. Harder, The effects of snow ventilation on chemical concentrations, in Chemical exchange between the atmosphere and polar snow, edited by $\mathrm{E}$. W. Wolff and R. C. Bales, pp. 403-451, NATO ASI Series Vol. I 43, Springer-Verlag, Heidelberg, 1996.

Watanabe, 0 ., Distribution of surface features of snow cover in Mizuho Plateau, in Glaciological studies in Mizuho Plateau, East Antarctica, 1969-1975, edited by T. Ishida, pp. 44-62, National Institute of Polar Research, Tokyo, 1978.

J. F. Bolzan, B. M. Csatho and C. J. van der Veen. Byrd Polar Research Center, 108 Scott Hall, 1090 Carmack Road, Columbus OH 43210-1002 (e-mail: bolzan.1@osu.edu; csatho@iceberg.mps. ohio-state.edu; vanderveen.1@osu.edu)

W. B. Krabill, Laboratory for Hydrospheric Processes, NASA/GSFC Wallops Flight Facility, Wallops Island VA 23337 (email: krabill@osb1.wff.nasa.gov)

(Received March 18, 1998; revised August 3, 1998; accepted August 28, 1998) 